\title{
Human Frontiers Science Program on table at Toronto summit
}

Tokyo

JAPAN's Human Frontiers Science Program will be on the table at the Toronto summit of Western nations to be held later this month. The summit is expected to focus on economic issues and the decision to include Frontiers, made at a presummit meeting in Toronto on 5 and 6 June, is largely symbolic. But it may help the Japanese government ministries and agencies involved to realize their dream of turning the programme into a major multilateral research organization.

Frontiers was first proposed by the Ministry of International Trade and Industry (MITI) in 1986 as a huge international bioscience project into which Japan would pour thousands of millions of dollars to develop new technology for the twenty-first century. But the Science and Technology Agency has since assumed prime responsibility for the programme, emphasis has switched to pure science and the proposed scale of the budget has been considerably reduced. Nevertheless, agency officials still entertain great ambitions for the programme.

Japan will, if necessary, put up all the funds for Frontiers in the initial phase, according to Tateo Arimoto, director for planning in the agency's Science and Technology Policy Bureau. The agency and MITI hope to get about $\$ 20$ million for Frontiers in fiscal year 1989 and these funds will probably be fed into a central organization to distribute international grants and fellowships, Arimoto says. But as the grants will be for three years and the fellowships for two, the Frontiers budget will have to rise two to threefold by 1991 .

Other Japanese ministries may join the programme from fiscal year 1990 and discussions are now under way between MITI, the agency and the Ministry of Education, Science and Culture. But Arimoto is also optimistic that other nations will join.

He says West Germany, France, Italy and the European Community have expressed willingness to contribute. Britain, on the other hand, is not expected to give any funds but is willing to provide scientists and, access to her research laboratories. Representatives of the US National Science Foundation, the National Institutes of Health and the National Academy of Sciences have also said they will cooperate. But William Graham, head of the White House Office of Science and Technology, has made it clear that the United States will not contribute funds in the initial phase, although he also welcomed the programme. And Arimoto says that whereas in the past representatives of other countries were scep- tical and said "you will do it", the attitude is now changing to "we will do it".

Arimoto foresees a loose international organization in the initial phase, perhaps with governments contributing funds to central Frontiers organizations in each participating country. But by the early 1990 s, he hopes that a multilateral organi- zation similar to the European Molecular Biology Organisation will be established. And this will help the flow of funds across Japan's borders, he says.

Japan's Prime Minister Noboru Takeshita is not expected to discuss any of these details at the summit. But inclusion of Frontiers is "very important politically", according to Arimoto, and will strengthen the agency's hand in negotiating the Frontiers budget with the Ministry of Finance later this year.

David Swinbanks

\section{Cuts in tax concessions for Australian R\&D}

Sydney

CuTs in tax concessions for investment in research and development $(R \& D)$ have been announced in the Australian federal government's May economic statement. The 150 per cent tax concession approved in 1985 will continue for the previously agreed period to 1991 . The concession will then drop to 100 per cent from June 1991.

Professor Frank Larkins, president of the Federation of Australian Scientific and Technological Societies (FASTS) believes that the federal government's decision may result in a reduction in industrial $R \& D$ unless other initiatives are set in motion.

Although there has been only a gradual increase in $R \& D$ investment since the concession were first introduced, it has mainly benefited companies with sizeable in-house research rather than smaller companies or universities. Helen Trincker, spokesperson for the Australian Vice-Chancellors Committee, says: "In the 1985-86 period, of the proportion of money invested under the 150 per cent tax cut scheme, only 4 per cent went to universities while 96 per cent of companies invested in their own institutions. To counteract this, we are creating a Council for Business/Higher Education Cooperative which will, hopefully, forge links between industry and universities. The trouble with industry is that they must recognize that research can be slow and they may not get returns on their investments for a couple of years."

Professor Larkins believes that greater incentives must be offered, now that tax concessions have been reduced, so that R\&D investment does not fall. "In the May statement, company tax was dropped from 49 to 39 per cent. This will mean an increase in profits, part of which could finance research. All companies with more than five employees should be required to contribute at least 1 per cent of their turnover directly to $R \& D$ spending."'

Tania Ewing

\section{Scandinavian killer algae outbreak}

\section{London}

A sERIOUs outbreak of poisonous algae in the seas around southern Scandinavia has stopped short of a widespread ecological disaster. Three weeks after the problem began, strong winds and currents have contributed to its recession, diluting the concentration of viable algae by 75 per cent in two days.

The poisonous gelatinous algae Chrysochromulina polylepsis have devastated marine life in the Kattegat and Skagerrak seas and cost the Norwegian fishing industry some $£ 120$ million, including the loss of 500 tonnes of salmon. Disaster committees have been set up by the Swedish, Danish and Norwegian governments and extra funds injected into marine research laboratories to accelerate the control of the algae, which was doubling overnight and spreading in enormous clumps at $25 \mathrm{~km}$ a day.

As a result of the episode, the Norwegians are now considering setting up many more land-based fish farms, where the environment can be better controlled.
The Swedes are urgently looking into the development of ecological early-warning systems, having recently been the victims of Chernobyl, of acid rain from other industrialized countries, and now of a possible water-borne pollution which could have caused the algae to flourish.

A spring bloom of marine algae is a natural event resulting from changing conditions in sea water. Particular algae establish themselves by exerting inhibitory effects on rival species as a result of their secretions, a potent toxin in the case of $C$. polylepsis. The surviving species are those best adapted to the prevailing conditions.

Proliferation is encouraged by increased concentrations of nitrate and phosphate washed into the sea as agricultural fertilizers and sewage. Rare strains of algae can become dominant as a result of water pollution by noxious chemicals, simply by growing more rapidly. Pollution carried by rivers from eastern Germany is being blamed for the provision of this perfect $C$. polylepsis medium, but this is probably an oversimplification.
Rosalind Cotter 